\title{
Maxing Out in China: Optimism or Attention?
}

\author{
Muhammad A. Cheema, Gilbert V. Nartea, and Yimei Man
}

\begin{abstract}
Bali, Cakici and Whitelaw (2011) document a MAX premium in the U.S. where stocks with the highest maximum daily returns (MAX) underperform stocks with the lowest MAX in the subsequent month. However, the source of this MAX premium is contentious. Fong and Toh (2014) find that the MAX premium exclusively follows high sentiment periods suggesting that it is driven by investor optimism during high sentiment periods. In contrast Cheon and Lee (2017) find that the MAX premium is stronger following low sentiment periods suggesting that it is driven by the attention-grabbing characteristic of high MAX stocks in low sentiment periods. We present evidence from China consistent with the MAX premium being driven by investor optimism during high sentiment periods.
\end{abstract}

\section{INTRODUCTION}

Bali et al. (2011) document a MAX premium in the U.S. where stocks with the highest maximum daily returns (MAX) underperform stocks with the lowest MAX in the subsequent month.They attribute this MAX premium to investor preference for lottery-like high MAX stocks resulting in an overpayment for such stocks. Cheon and Lee (2017) affirm the existence of a MAX premium in a multi-country study and show the MAX premium is higher for countries with high levels of individualism using Hofstede's (2010) country individualism index as a proxy for investor overconfidence. For example, they report a MAX premium of $1.96 \%$ per month for the U.S. which has the highest individualism index, and an insignificant MAX premium of $0.01 \%$ per month for China, which ranks among the lowest on individualism index. However, the absence of MAX premium for China reported in Cheon 
and Lee is inconsistent with the significant MAX effect reported in other studies (e.g. Carpenter, Lu and Whitelaw, 2017, Nartea, Kong and Wu, 2017, Wan, 2018).

In a related strand in the literature, Fong and Toh (2014) find that the MAX premium exclusively follows high sentiment periods. They suggest that this is consistent with the view that the MAX premium is driven by investor overoptimism about the future payoffs of high MAX stocks when sentiment is high, resulting in low returns following high sentiment periods. However, Cheon and Lee (2017) find that the MAX premium is more pronounced following low sentiment periods. Using volatility metrics as proxies for investor sentiment, they find that the MAX premium is higher following high U.S. VIX, high U.S. volatililty, and high world volatility periods. Cheon and Lee argue that their results are consistent with the view that the MAX premium is driven by the 'attention-grabbing' (Barber and Odean, 2008) feature of high MAX stocks rather than by the investor overoptimism.

In light of the contradictory evidence in the literature, we investigate the relation between investor sentiment and the MAX effect in China and test whether the MAX premium is driven by investor optimism in high sentiment periods, or by the attention-grabbing feature of high MAX stocks in low sentiment periods. ${ }^{1}$ The Chinese stock markets are interesting case studies since they are dominated by retail investors who might be more prone to behavioural biases, e.g., overoptimism and attention-bias. In as much as China has a very low individualism index, we first test whether the MAX effect is absent or weak in this market as suggested by Cheon and Lee (2017). Next, to mitigate the concern that the U.S. and global based sentiment proxies in Cheon and Lee might not be valid for China, we develop an

\footnotetext{
${ }^{1}$ Other studies related to the extreme value literature deal with modelling and predicting tail values (see for example, Gençay and Selçuk, 2006, Gençay and Selçuk, 2004, Gençay, Selçuk and Ulugülyağci, 2003). By contrast, our study is concerned with shedding light on the source of the MAX premium that prevails when stocks with the highest maximum daily returns in the current month subsequently underperform stocks with the lowest maximum daily returns.
} 
investor sentiment index for China and employ this to investigate the relation between sentiment and the MAX premium.

We find consistent with other studies (e.g. Carpenter et al., 2017, Nartea et al., 2017, Wan, 2018), but contrary to Cheon and Lee (2017), that the MAX premium in China is significant and is similar in magnitude to that in the U.S. markets. Given the wide disparity in individualism index scores between China and the U.S., this result is inconsistent with the suggestion that the MAX premium is higher in countries with more individualistic investors. More importantly, we find that the MAX premium in China is stronger following high (not low) sentiment periods. Therefore we present evidence supportive of the view that the MAX premium is driven by investor optimism in high sentiment periods contrary to view that it is driven by the attention-grabbing feature of high MAX stocks.

\section{DATA AND METHODS}

We collect stock level data on common stocks traded in the Shanghai (SSE) and Shenzhen (SZSE) stock exchanges of China from DataStream from June 1997 to June 2017. Following the literature (e.g., Chui, Titman and Wei, 2010, Carpenter et al., 2017, Cheema and Nartea, 2017), we only include A-shares in our sample. We apply several screening procedures suggested in the literature (e.g., Ince and Porter, 2006, Karolyi, Lee and Van Dijk, 2012, Lee, 2011) to clean our data and provide the details in Appendix A. ${ }^{2}$ Our sample starts with 651 stocks and ends with 3041 stocks. We estimate the daily and monthly stock returns, adjusted for dividends, from the stock return index (RI).

Following Cheema, Man and Szulczyk (2018), we develop a sentiment levels index by estimating the first principal component from the residuals of three individual sentiment proxies taken from the SSE, namely, the price-earnings ratio (PE), turnover ratio (TO), and

\footnotetext{
${ }^{2}$ Cheon and Lee (2017) applies the same screening procedures to clean their data.
} 
the number of newly opened individual investor accounts (IA). ${ }^{3}$ We collect the PE ratio, IA, and macroeconomic variables from the CEIC database and TO from DataStream. The resulting sentiment levels index is:

$S T M_{t}=0.544 P E_{t}+0.588 T O_{t}+0.598 I A_{t}$

The coefficients in equation (1) can be interpreted as the loading or the weight by which each standardized original variable should be multiplied to get the sentiment index. The first principal component of our sentiment levels index explains $76.79 \%$ of the sample variance.

At the beginning of each month $t+1$, we form decile portfolios based on the maximum (MAX) daily return in month $t$. Portfolio $\mathrm{P} 1$ (P10) is the decile portfolio with lowest (highest) MAX. P1-P10 is a zero-investment portfolio that is long (short) in the low (high) MAX portfolio. $^{4}$

Apart from raw returns (MAX premium) we also calculate Fama-French risk-adjusted returns (MAX Alpha or simply alpha) of the P1-P10 zero-investment portfolio each month $t+1$ as

$$
M A X_{t+1}^{a d j}=M A X_{t+1}-\beta_{m} \cdot R M R F_{t+1}-\beta_{s} \cdot S M B_{t+1}-\beta_{h} \cdot H M L_{t+1}
$$

where RMRF is the excess return of the value-weighted market portfolio of A-shares over the 30-day inter-bank offer rate, SMB is the small-minus-big size factor, and HML is the highminus-low book-to-market factor. The details for the construction of RMRF, SMB and HML factors are provided in Appendix B. $\beta_{m}, \beta_{s}$ and $\beta_{h}$ are the estimated loadings obtained from the time-series regression of the MAX premium on the Fama-French (FF) risk factors plus a constant. We subtract from the monthly time-series of raw MAX premium, the monthly time-

\footnotetext{
${ }^{3}$ Following the literature (e.g., Baker and Wurgler, 2007, Chen, Chong and She, 2014), we scale individual sentiment proxies by their prior six-month moving averages. To obtain residuals, we regress each proxy on a set of macro-economic variables, namely, the growth of industrial production (IP), growth of money supply (MS2), 30-day inter-bank offer rate, recession indicator and foreign exchange rate (RMB/USD).

${ }^{4}$ Our findings remain unchanged if we form quintile portfolios instead.
} 
series of Fama-French three factors that are multiplied by their respective estimated loadings, $\beta_{m}, \beta_{s}$ and $\beta_{h}$

\section{EMPIRICAL FINDINGS}

Figure 1 plots the highest maximum daily returns and shows that the maximum daily returns generally do not exceed a price change limit of $10 \%$ which was implemented in December 1996. However, there are certain days when the maximum daily returns are higher than $10 \%$ which could be due to the fact that daily and monthly returns are adjusted for dividends. ${ }^{5}$

Panel A of Table 1 reports the unconditional equally weighted (EW) and value weighted (VW) returns of P1, P10, P1-P10, and the FF-adjusted returns (alpha) of P1-P10. We find large and significant EW, and VW MAX premiums and alphas. For example, the EW (VW) MAX premium is $1.03 \%(0.66 \%)$ per month. These MAX premia are very similar in magnitude to those in the U.S. markets where Bali et al. (2011) report EW (VW) MAX returns of $1.02 \%(0.62 \%)$ per month over their sample period of 1926 to 2015 . Surprisingly, our unconditional MAX returns are inconsistent with Cheon and Lee (2017) who report almost zero MAX returns in China, also using DataStream even as we form decile portfolios similar to them. However, our unconditional MAX returns are consistent with those reported in Nartea et al. (2017) and Wan (2018), though they use CSMAR as an alternative data source. ${ }^{6}$ As a robustness test we also used CSMAR data with similar results. Therefore, we are unable to confirm the results reported in Cheon and Lee (2017). We trust our comprehensive and carefully screened dataset so the difference between our results and those of Cheon and Lee (2017) could be due to different time periods covered in the papers since their sample is from 1992 to 2012. To address this concern, we restrict our sample from 1992

\footnotetext{
${ }^{5}$ To ensure that daily returns exceeding $10 \%$ are not because of data recording errors of DataStream, we set stocks with daily returns greater than $10 \%$ equal to $10 \%$ and find similar results. We do not report these results to save space.

${ }^{6}$ CSMAR stands for Chinese Stock Market and Accounting Research
} 
to 2012 and find even higher MAX returns. ${ }^{7}$ Furthermore, we also examine whether our results are robust to the exclusion of extreme periods. There are two extreme periods in our sample, the 2008-2009 financial crisis and the extreme volatile period in 2016. We exclude these two periods from our sample and still find similar results. ${ }^{8}$

Next, we examine the cross-sectional relation between expected returns and MAX at the firm level using Fama-Macbeth regressions and control for multiple factors. We estimate the following model:

$R_{i, t+1}=\alpha+\beta_{1, t} M A X_{i, t}+\beta_{2, t} I V_{i, t}+\beta_{3, t} S I Z E_{i, t}+\beta_{4, t} B T M_{i, t}+\beta_{5, t} P R I C E_{i, t}+$ $\beta_{6, t} M O M_{i, t}+\mu_{t+1}$

where $R_{i, t+1}$ is the realized return on stock $i$ in month $t+1$. All the explanatory variables are constructed prior to the month $t+1$. Panel B shows that MAX is negatively and significantly related to the cross-section of expected returns with an average slope coefficient of $-16.94(t-$ stat=-5.67) even when we control for other firm characteristics. In sum, our results in Panels $\mathrm{A}$ and $\mathrm{B}$ show that the MAX premium in China is large and significant and is similar in magnitude to the MAX premium reported by Bali et al. (2011) for the U.S. markets. In as much as China has among the lowest levels of Hofstede's individualism index while the U.S. has the highest, our results are inconsistent with the suggestion in Cheon and Lee (2017) that differences in the MAX premium across countries can be explained by levels of individualism.

\footnotetext{
${ }^{7}$ For example, we find EW MAX premium of $2.42 \%$ per month $(t$-stat=1.94). However, this increase in MAX premium is related to the early years of the sample period (1992-1996) where EW MAX premium is $6.46 \%$ per month. The number of stocks available in early years of the sample is quite low. For example, there were only 13 (50) valid stocks available in January (December) 1992. The Chinese stock markets had a quite small number of stocks available in the early years of their history, i.e., less than 100 stocks were listed on Chinese stock markets until 1993. Therefore, most of the studies on China do not include years earlier than 1994 in their sample (Jacobs, 2016, Carpenter et al., 2017, Wan, 2018, Nartea et al., 2017).

${ }^{8} \mathrm{We}$ thank the reviewer for suggesting this test. We find EW MAX premium of $0.90 \%$ per month $(t$-stat $=2.94)$ after excluding the 2008-2009 financial crisis period and 1.20\% per month ( $t$-stat=3.39) after excluding 2016.
} 
Panel C reports the MAX premium conditioned on sentiment. We classify a period as High (Low) sentiment if the sentiment index is above (below) the median sentiment value. We find that the EW MAX premium is significant only following high sentiment periods. For example, the EW MAX premium following high sentiment periods is $1.85 \%$ per month $(t$ stat=3.83), whereas the EW MAX premium following low sentiment periods is only $0.22 \%$ per month $(t$-stat $=0.51)$. Therefore, the MAX premium following high sentiment periods is significantly higher than that following low sentiment by $1.63 \%$ per month $(t$-stat $=2.30)$. Furthermore, the FF-adjusted MAX premium (alpha) is also significant only following high sentiment periods; and MAX alpha following high sentiment is significantly higher than that following low sentiment by $2.37 \%$ per month $(t$-stat=4.21). The VW MAX premium is also statistically significant only following high sentiment periods. Though the MAX premium following high sentiment is higher than that following low sentiment periods by $0.84 \%$ per month, it is statistically insignificant. However, the difference in alpha between high and low sentiment periods is significant at $1.62 \%$ per month $(t$-stat=2.27). On balance, we find that the MAX premium following high sentiment periods is larger than the MAX premium following low sentiment periods. This is contrary to the suggestion in Cheon and Lee (2017) that the MAX premium is higher following low sentiment periods and that it is the stronger attention to high MAX stocks during low sentiment periods that drive the pricing of lotterytype stocks. One obvious limitation in Cheon and Lee (2017) is that instead of using a direct sentiment index, they use the U.S. VIX, U.S. volatility, and world market volatility to infer investor sentiment for all their sample countries. The U.S.-based proxies may not be valid for China while the world market volatility might only be a crude proxy for sentiment in the Chinese stock markets. Our results which are based on a China-specific sentiment levels index are more consistent with Fong and Toh (2014) who find in the U.S. markets that MAX premium exclusively follows high sentiment periods. 
The results in Panel $\mathrm{C}$ were obtained by averaging MAX returns within high and low sentiment months, using sentiment as a binary measure. As a robustness test we employ predictive regressions:

$$
\begin{aligned}
& R_{P 1-P 10, t+1}=\alpha+b S_{t}+\mu_{t+1} \\
& R_{P 1-P 10, t+1}=\alpha+b S_{t}+c M K T_{t+1}++d S M B_{t+1}+e H M L_{t+1}+\mu_{t+1}
\end{aligned}
$$

In equation 4 we regress the EW MAX premium (P1-P10) on just the lagged sentiment index whereas in equation 5 we regress on lagged sentiment index and the FamaFrench risk factors. ${ }^{9}$ We report the results in Panel D. The coefficient of lagged sentiment based on equation 4 is $0.80(t$-stat=2.06). The coefficient of lagged sentiment based on equation 5 which is adjusted for exposures to the Fama-French risk factors is $1.64(t$ stat=5.66). These results indicate that the MAX premium is higher following high (not low) sentiment periods and are strongly supportive of our main results.

In sum, our results are more consistent with the view that the MAX premium is due to a preference for lottery-like high MAX stocks that is driven by investor optimism in periods of high investor sentiment, rather than due to the attention-grabbing feature of high MAX stocks in periods of low sentiment.

\section{CONCLUSION}

Fong and Toh (2014) show that the MAX premium in the U.S. exclusively follows high sentiment periods suggesting it is due to increased over-optimism among investors during high sentiment periods. In contrast Cheon and Lee (2017) find that the MAX premium is stronger in periods of low sentiment suggesting that the premium is driven by the attentiongrabbing characteristic of high MAX stocks. Using a sentiment levels index for China that we

\footnotetext{
${ }^{9}$ Our results remain qualitatively similar when we use VW MAX premium instead of EW MAX premium.
} 
develop, we find that the MAX premium is stronger following high than low investor sentiment periods. Therefore, our results are more consistent with the MAX premium being driven by investor optimism in high sentiment periods than by the attention-grabbing feature of high MAX stocks in low sentiment periods. 


\section{References}

Baker, M. and J. Wurgler (2007), Investor sentiment in the stock market. National Bureau of Economic Research Cambridge, Mass., USA.

Bali, T. G., N. Cakici and R. F. Whitelaw (2011), 'Maxing out: Stocks as lotteries and the cross-section of expected returns', Journal of Financial Economics, 99, 427-46.

Barber, B. M. and T. Odean (2008), 'All That Glitters: The Effect of Attention and News on the Buying Behavior of Individual and Institutional Investors', The Review of Financial Studies, 785-818.

Carpenter, J. N., F. Lu and R. F. Whitelaw (2017), The real value of China's stock market. New York University, NewYork. .

Cheema, M. A., Y. Man and K. R. Szulczyk (2018), 'Does investor sentiment predict the near-term returns of the Chinese stock market?', Available at SSRN: http://dx.doi.org/10.2139/ssrn.3078449.

Cheema, M. A. and G. V. Nartea (2017), 'Momentum returns, market states, and market dynamics: Is China different?', International Review of Economics \& Finance, 50, 8597.

Chen, H., T. T. L. Chong and Y. She (2014), 'A principal component approach to measuring investor sentiment in China', Quantitative Finance, 14, 573-79.

Cheon, Y.-H. and K.-H. Lee (2017), 'Maxing Out Globally: Individualism, Investor Attention, and the Cross Section of Expected Stock Returns', Management Science.

Chui, A. C., S. Titman and K. J. Wei (2010), 'Individualism and momentum around the world', The Journal of Finance, 65, 361-92.

Fama, E. F. and K. R. French (1993), 'Common risk factors in the returns on stocks and bonds', Journal of Financial Economics, 33, 3-56.

Fama, E. F. and K. R. French (2012), 'Size, value, and momentum in international stock returns', Journal of Financial Economics, 105, 457-72.

Fong, W. M. and B. Toh (2014), 'Investor sentiment and the MAX effect', Journal of Banking \& Finance, 46, 190-201.

Gençay, R. and F. Selçuk (2004), 'Extreme value theory and Value-at-Risk: Relative performance in emerging markets', International Journal of Forecasting, 20, 287-303.

Gençay, R. and F. Selçuk (2006), 'Overnight borrowing, interest rates and extreme value theory', European economic review, 50, 547-63.

Gençay, R., F. Selçuk and A. Ulugülyağci (2003), 'High volatility, thick tails and extreme value theory in value-at-risk estimation', Insurance: Mathematics and Economics, 33, 337-56.

Ince, O. S. and R. B. Porter (2006), 'Individual equity return data from Thomson Datastream: Handle with care!', Journal of Financial Research, 29, 463-79.

Jacobs, H. (2016), 'Market maturity and mispricing', Journal of Financial Economics, 122, 270-87.

Karolyi, G. A., K.-H. Lee and M. A. Van Dijk (2012), 'Understanding commonality in liquidity around the world', Journal of Financial Economics, 105, 82-112.

Lee, K.-H. (2011), 'The world price of liquidity risk', Journal of Financial Economics, 99, 136-61.

Nartea, G. V., D. Kong and J. Wu (2017), 'Do extreme returns matter in emerging markets? Evidence from the Chinese stock market', Journal of Banking \& Finance, 76, 189-97.

Wan, X. (2018), 'Is the idiosyncratic volatility anomaly driven by the MAX or MIN effect? Evidence from the Chinese stock market', International Review of Economics \& Finance, 53, 1-15. 


\section{Table 1: MAX Effect and Investor Sentiment}

At the beginning of every month $t+1$, we sort stocks into decile portfolios based on the maximum daily returns (MAX) of each stock in month $t$. The lowest decile (P1) contains the stocks with the lowest MAX, and the highest decile (P10) contains the stocks with the highest MAX. Panel A reports the monthly average returns and FF alphas of P1, P10 and P1-P10 portfolios. Panel B reports the estimates of Fama-Macbeth regression where the dependent variable is monthly stock returns of $t+1$ and independent variables are MAX (maximum daily returns in month $t$ ), firm IV (standard deviation of residuals obtained from the regressing monthly returns against the Fama-French factors over the past 12 months), log of Size (market capitalization at the end of month $t$ ), $\log$ of BTM (book-to-market ratio at the end of month $t$ ), , log Price (closing price at the end of month $t$ ) and MOM (cumulative returns over past 11 months, $t-1$ to $t-11$ ). Panel $\mathrm{C}$ reports the monthly average returns and FF alphas of P1, P10 and P1-P10 portfolios following high and low investor sentiment. A high (low) investment month is one where sentiment is above (below) the sample median value. Panel D report the estimates of $b$ in the regressions $R_{P 1-P 10, t+1}=\alpha+b S_{t}+\mu_{t+1}(1)$ and $R_{P 1-P 10, t+1}=\alpha+b S_{t}+c M K T_{t+1}+d S M B_{t+1}+$ $e H M L_{t+1}+\mu_{t+1}$ (2). MKT, SMB and HML are the contemporaneous returns on Fama-French risk factors. The Newey-West adjusted $t$-statistics are provided in parentheses. The sample period is from June 1997 to June 2017.

\begin{tabular}{|c|c|c|c|c|c|c|}
\hline \multicolumn{7}{|c|}{ Panel A: Unconditional Max Effect } \\
\hline & \multicolumn{2}{|c|}{ Equally weighted returns } & \multirow[b]{2}{*}{ Kurtosis } & \multicolumn{2}{|c|}{ Value weighted returns } & \multirow[b]{2}{*}{ Kurtosis } \\
\hline & Mean & Skewness & & Mean & Skewness & \\
\hline $\mathrm{P} 1$ & $\begin{array}{l}2.05 \\
(4.06)\end{array}$ & 0.91 & 2.63 & $\begin{array}{l}0.85 \\
(1.88)\end{array}$ & 0.97 & 3.03 \\
\hline $\mathrm{P} 10$ & $\begin{array}{l}1.02 \\
(1.51)\end{array}$ & 0.38 & 0.94 & $\begin{array}{l}0.19 \\
(0.30)\end{array}$ & 0.23 & 0.78 \\
\hline P1-P10 & $\begin{array}{l}1.03 \\
(3.43)\end{array}$ & -0.22 & 2.86 & $\begin{array}{l}0.66 \\
(1.74)\end{array}$ & -0.22 & 1.48 \\
\hline Alpha & $\begin{array}{l}1.70 \\
(5.03)\end{array}$ & & & $\begin{array}{l}1.33 \\
(3.29)\end{array}$ & & \\
\hline
\end{tabular}

\begin{tabular}{lllllll}
\hline \multicolumn{7}{l}{ Panel B: Estimates of firm-level Fama-Macbeth Regression } \\
\hline MAX & IV & MV & BTM & Price & MOM & ADJ Rsq \\
\hline-16.94 & -1.07 & -0.59 & 0.82 & -1.26 & 0.85 & 0.082 \\
$(-5.67)$ & $(-0.71)$ & $(-3.66)$ & $(5.35)$ & $(-8.13)$ & $(2.83)$ & \\
\hline
\end{tabular}

\begin{tabular}{|c|c|c|c|c|c|c|}
\hline \multicolumn{7}{|c|}{ Panel C: Max Effect following High and Low Sentiment Periods } \\
\hline & \multicolumn{2}{|c|}{ Equally weighted returns } & \multirow[b]{2}{*}{ Diff } & \multicolumn{2}{|c|}{ Value weighted returns } & \multirow[b]{2}{*}{ Diff } \\
\hline & High & Low & & High & Low & \\
\hline \multirow{2}{*}{ P1 } & 3.61 & 0.49 & & 1.85 & -0.16 & \\
\hline & $(4.64)$ & $(0.79)$ & & $(2.57)$ & $(-0.31)$ & \\
\hline \multirow{2}{*}{ P10 } & 1.77 & 0.27 & & 0.78 & -0.40 & \\
\hline & $(1.77)$ & $(0.30)$ & & $(0.83)$ & $(-0.48)$ & \\
\hline \multirow{2}{*}{ P1-P10 } & 1.85 & 0.22 & 1.63 & 1.08 & 0.24 & 0.84 \\
\hline & $(3.83)$ & $(0.51)$ & $(2.30)$ & (1.73) & $(0.43)$ & $(0.99)$ \\
\hline \multirow{2}{*}{ Alpha } & 2.88 & 0.51 & 2.37 & 2.14 & 0.52 & 1.62 \\
\hline & (6.68) & (1.58) & $(4.21)$ & $(3.87)$ & $(1.32)$ & $(2.27)$ \\
\hline
\end{tabular}

Panel D: Regression of Max Returns (Low-High) on Sentiment (1) and Sentiment and FF-factors (2)

\begin{tabular}{|c|c|c|c|}
\hline \multicolumn{2}{|c|}{ Regression (1) } & \multicolumn{2}{|c|}{ Regression (2) } \\
\hline$\overline{b^{\wedge}}$ & $t$-statistics & $b^{\wedge}$ & $t$-statistics \\
\hline 0.80 & $(2.06)$ & 1.64 & $(5.66)$ \\
\hline
\end{tabular}


Figure 1: This figure plots highest maximum (MAX) daily returns.

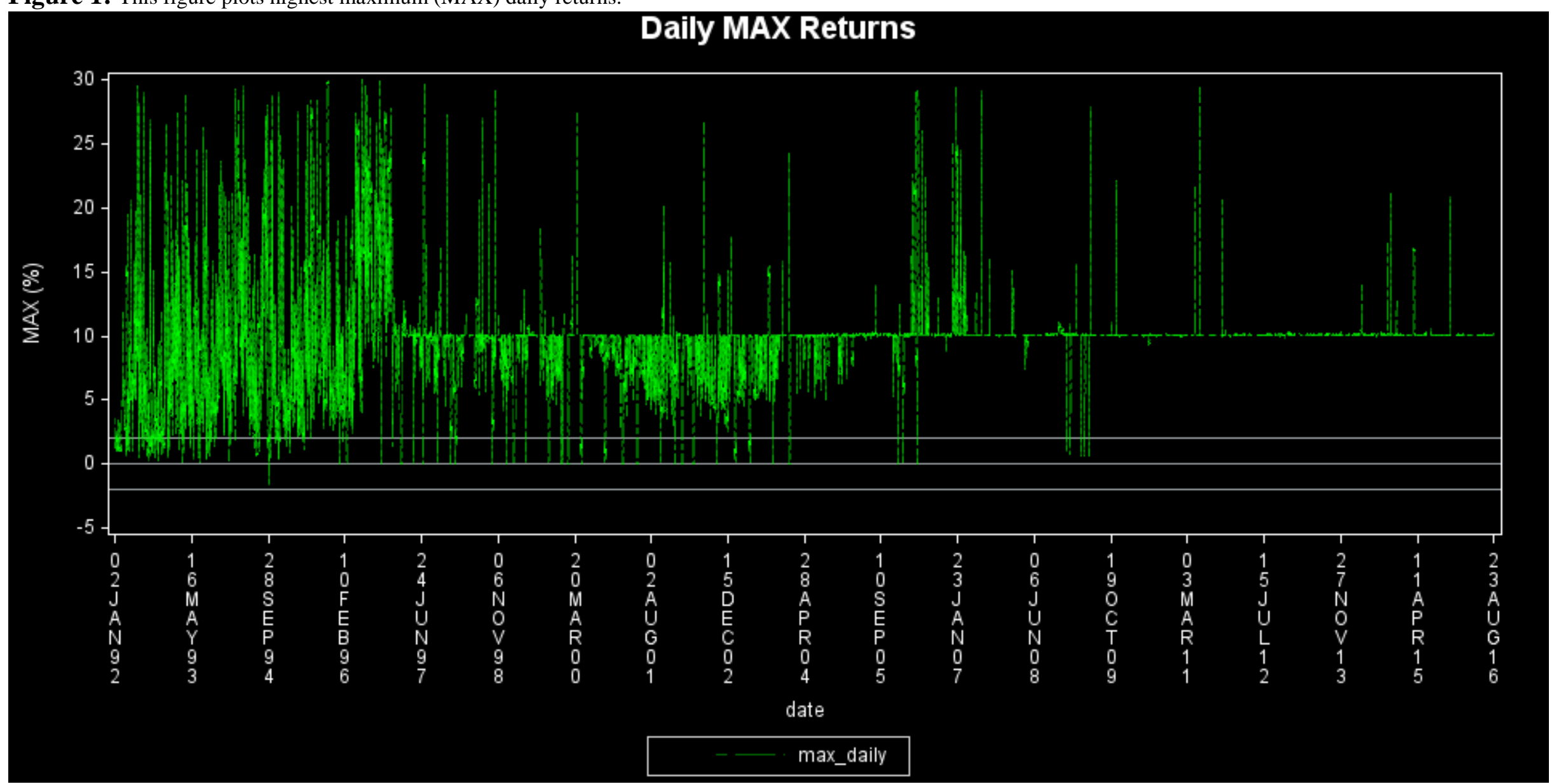




\section{Appendix A: Data screening}

We apply following filters suggested in the literature (e.g., Ince and Porter, 2006, Karolyi et al., 2012, Lee, 2011) to clean our data:

1. Exchanges, Security type, Currency: We include all the common stocks (TYP=EQ) traded at the two major exchanges for China (Shanghai Stock Exchange and Shenzhen Stock Exchange). Furthermore, we restrict our data to the primary quotation of a security (ISINID=P); the security with the biggest market capitalization (MAJOR=Y), and traded in local currency, Chinese Yuan (A-shares).

2. Filter non-common equity securities using security names: Restricting Type=EQ might not exclude all non-common stocks (Ince and Porter, 2006). Therefore, following Lee (2011) and Karolyi et al. (2012), we manually examine names to find non-common stocks. We eliminate the stocks if the names include "REIT," "REAL EST," "GDR," "PF," "PREF," “PRF, "“ADS,"“RESPT,"“UNIT,"“TST,"“TRUST,"“INCOMEFD,” “INCOME FUND,” "UTS," "RST," “CAP.SHS," "INV," "HDG," "SBVTG," "VTG.SAS," "GW.FD," "VCT," “RTN.INC," “ORTF," “HI.YIELD," "PARTNER," "HIGH INCOME," "INC.\&GROWTH,” and "INC.\&GW." As these terms might indicate preferred stock, mutual funds, index funds, warrants, investment trusts, Real Estate Investment Trusts (REITs) and other forms of noncommon stocks.

3. Filter data errors in returns: We apply several screening procedures to clean monthly and daily return $\left(\mathrm{R}_{\mathrm{t}}\right)$ data as suggested by Ince and Porter (2006) and others. First, we set any daily (monthly) returns as missing if the total return index for either day (month) $t$ or $t-1$ is less than or equal to 0.01 . Secondly, we set any daily (monthly) returns above $200 \%$ (300\%) as missing that is reversed within one month. More specifically, if daily (monthly) $\mathrm{R}_{\mathrm{t}}$ or $\mathrm{R}_{\mathrm{t}-1}$ is greater than (200\%) 300\%, and $\left(\mathrm{R}_{\mathrm{t}}+1\right)\left(\mathrm{R}_{\mathrm{t}-1}+1\right)-1<50 \%$, then we set both $\mathrm{R}_{\mathrm{t}}$ and $\mathrm{R}_{\mathrm{t}-1}$ as missing. 
3. Drop non-trading days: Following Lee (2011) and Karolyi et al. (2012), we drop nontrading days from the sample which are defined as a day when more than $90 \%$ of stocks in Shanghai and Shenzhen exchanges have zero returns.

\section{Appendix B: Construction of Fama-French three Factors}

The excess market return factor (RMRF)is the value-weighted market return for A-shares minus the one-month 30-day inter-bank offer rate. The SMB and HML factors are constructed using the six value-weighted portfolios formed on size and the book equity to market equity (BE/ME) ratio at the end of each June. Size is the market capitalization at the end of the June of year $y$ and BE/ME for June of year $y$ is the book equity for the last fiscal year ended in $y$-1 divided by ME for December of $y-1$. We exclude stocks with less than or equal to zero market capitalization and a negative BE/ME ratio to estimate SMB and HML factors. Following Fama and French (2012), we sort stocks into two size groups based on $90 \%$ of the aggregate market capitalization as the breakpoint where the top (bottom) $90 \%$ $(10 \%)$ of aggregate market capitalization is classified as big (small). We also sort stocks into three $\mathrm{BE} / \mathrm{ME}$ portfolios based on 30th and 70th percentiles of $\mathrm{BE} / \mathrm{ME}$ ratio where stocks above (below) the 70th (30th) percentile are classified as value (growth) stock. The intersection of size and BE/ME portfolios result into six value-weighted portfolios. As in Fama and French (1993), SMB is the average return on the three small portfolios minus the average return on the three big portfolios whereas, HML is the average return on the two value portfolios minus the average return on the two growth portfolios. 